\title{
FAKTOR-FAKTOR YANG MEMPENGARUHI RETURN SAHAM PERUSAHAAN MANUFAKTUR YANG TERDAFTAR DI BURSA EFEK INDONESIA PERIODE 2015-2017
}

\author{
Dylen Limto \\ Program Studi Magister Manajemen Universitas Tarumanagara \\ dylen.lim@gmail.com \\ Carunia Mulya Firdausy \\ Program Studi Magister Manajemen Universitas Tarumanagara
}

Masuk : 06-12-2019, revisi : 21-12-2019 diterima untuk diterbitkan : 21-12-2019

\begin{abstract}
The purpose of this research is to analyze the effect of Earning Per Share, Debt to Equity Ratio, Return on Assets, and Current Ratio on Stock Return in manufacturing companies listed in Indonesia Stock Exchange for the period of 2015 until 2017. This research used 198 data from manufacturing companies listed in Indonesia Stock Exchange, selected using purposive sampling method. The statistical method used to analyze the data in this research is multiple linear regression. The result of this research shows that earning per share and debt to equity ratio have no significant effect on stock return, return on assets and current ratio have significant effect on stock return.
\end{abstract}

Keywords : Earning Per Share, Debt to Equity Ratio, Return on Assets, Current Ratio, and Stock Return

Abstrak : Tujuan penelitian ini yaitu untuk menganalisis pengaruh Earning Per Share, Debt to Equity Ratio, Return on Assets, dan Current Ratio terhadap Return Saham pada perusahaan manufaktur yang terdaftar di Bursa Efek Indonesia pada periode 2015-2017. Penelitian ini menggunakan 198 data dari perusahaan manufaktur yang terdaftar di Bursa Efek Indonesia yang dipilih dengan metode purposive sampling. Metode statistik yang digunakan dalam penelitian ini adalah regresi linier berganda. Hasil penelitian menunjukkan bahwa earning per share dan debt to equity ratio tidak memiliki pengaruh yang signifikan terhadap return saham, sedangkan return on assets dan current ratio memiliki pengaruh yang signifikan terhadap return saham.

Kata Kunci : Earning Per Share, Debt to Equity Ratio, Return on Assets, Current Ratio, dan Return Saham

\section{PENDAHULUAN}

Perekonomian yang semakin berkembang mendorong individu maupun perusahaan untuk ber investasi. Investasi adalah komitmen atas sejumlah dana atau sumber daya lainnya yang dilakukan pada saat ini, dengan tujuan memperoleh keuntungan atau return di masa datang (Tandelilin, 2010). Pertimbangan utama dalam berinvestasi dapat memberikan keuntungan (return) saham bagi investor. Return saham yang tinggi menjadi salah satu daya tarik bagi seorang investor untuk menanamkan dananya di pasar modal. Semakin tinggi return atau keuntungan yang diperoleh, maka semakin baik posisi pemilik perusahaan (Husnan, 1998 dalam Arista dan Astohar, 2012). Return saham merupakan suatu faktor yang mempengaruhi minat investor untuk melakukan suatu investasi dalam suatu perusahaan, dengan tingginya tingkat pengembalian yang diberikan oleh perusahaan kepada investor, menunjukkan bahwa perusahaan tersebut memiliki kinerja yang baik. 
Di Indonesia terdapat pasar modal yang bernama Bursa Efek Indonesia (BEI). Salah satu sektor yang terdapat di pasar modal adalah sektor manufaktur yang memiliki jumlah emiten terbesar di BEI. Perusahaan manufaktur dituntut untuk memiliki dana yang cukup agar perusahaan dapat bersaing dan bertahan. Salah satu cara yang diambil perusahaan yaitu dengan melakukan penjualan saham perusahaan kepada masyarakat melalui pasar modal. Pasar modal memiliki peran penting dalam meningkatkan dan mendorong pertumbuhan, dan stabilitas ekonomi karena memiliki fungsi ekonomi dan fungsi keuangan (Hadi, 2013).

Dalam pemilihan saham mana yang dipilih, para investor membutuhkan informasi tentang kondisi dan kinerja keuangan perusahaan. Analisis laporan keuangan merupakan alternatif untuk menguji apakah informasi keuangan bermanfaat untuk melakukan prediksi harga saham dan penilaian mengenai kesehatan keuangan perusahaan serta kinerja keuangan. Kinerja keuangan perusahaan yang dipilih oleh investor dapat dinilai oleh investor dengan melakukan penilaian dan analisis terhadap rasio - rasio seperti earning per share, debt to equity ratio, return on assets dan aktivitas yang didapat dari laporan keuangan perusahaan (Husein dan Mahfud, 2015:2).

Oleh karena itu, studi ini bertujuan untuk mengetahui signifikansi pengaruh variabel Earning Per Share (EPS), Debt to Equity Ratio (DER), Return on Assets (ROA), dan Current Ratio (CR) secara bersama-sama, maupun masing-masing terhadap return saham perusahaan manufaktur yang terdaftar di Bursa Efek Indonesia periode 2015-2017.

\section{TINJAUAN PUSTAKA}

Return saham adalah tingkat keuntungan yang dinikmati oleh pemodal atas suatu investasi yang dilakukan (Ang, 1997). Keuntungan atau kerugian dalam berinvestasi saham sangat dipengaruhi oleh kemampuan investor menganalisis keadaan harga saham merupakan penilaian sesaat yang dipengaruhi oleh banyak faktor termasuk diantaranya kondisi (performance) dari perusahaan, kendala-kendala eksteral, kekuatan penawaran dan permintaan saham di pasar, serta kemampuan investor dalam menganalisis investasi saham (Arista, Astohar, 2012).

Return saham berbanding positif dengan risiko, semakin besar risiko yang ditanggung oleh investor, maka keuntungan akan semakin besar, begitu juga sebaliknya. Komponen return terdiri dari dua jenis yaitu current income (pendapatan lancar), dan Capital Gain (keuntungan selisih harga). Current income merupakan keuntungan yang diperoleh melalui pembayaran yang bersifat periode seperti pembayaran bunga obligasi, dividen dan sebagainya. Current income disebut sebagai pendapatan lancar, karena keuntungan yang diterima biasanya dalam bentuk kas, sehingga dapat diuangkan secara cepat, seperti bunga atau jasa giro, dan dividen tunai, juga dapat dalam bentuk setara kas seperti bonus atau dividen saham yaitu dividen yang dibayarkan dalam bentuk saham dan dapat dikonversikan menjadi uang kas (Brigham dan Houston, 2006:215)

Menurut Samsul (2006:200), faktor-faktor yang mempengaruhi return saham terdiri atas faktor makro dan faktor mikro. Faktor makro yaitu faktor yang berada di luar perusahaan, yaitu: (1) Faktor makro ekonomi yang meliputi tingkat bunga umum domestik, tingkat inflasi, kurs valuta asing dan kondisi ekonomi internasional, (2) Faktor non ekonomi yang meliputi peristiwa politik dalam negeri, peristiwa politik di luar negeri, peperangan, demonstrasi massa dan kasus lingkungan hidup.Lalu Faktor mikro yaitu faktor yang berada di dalam perusahaan itu sendiri, yaitu: (1) Laba bersih per saham, (2) Nilai buku per saham, (3) Rasio utang terhadap ekuitas, Dan rasio keuangan lainnya.

Menurut Darmaji, Tjiptono, dan Fakhruddin (2012) Earning Per Share menggambarkan profitabilitas perusahaan yang tergambar pada setiap lembar saham. Semakin tinggi nilai EPS tentu saja menyebabkan semakin besar laba dan kemungkinan peningkatan jumlah dividen yang diterima pemegang saham. Hal ini akan menarik perhatian investor sehingga banyak 
investor membeli saham perusahaan tersebut yang akan berpengaruh terhadap meningkatnya harga saham dan return saham yang akan meningkat pula.

Menurut Ross et al (2003), Debt to Equity Ratio (DER) merupakan perhitungan sederhana yang membandingkan total hutang perusahaan dari modal pemegang saham. DER merupakan rasio yang membandingkan total hutang dengan total ekuitas dari pemegang saham. Dengan demikian, DER juga dapat memberikan gambaran mengenai struktur modal yang dimiliki oleh perusahaan sehingga dapat dilihat tingkat risiko tak terbayarkan suatu hutang.

Return On Asset (ROA) merupakan salah satu rasio profitabilitas yang penting digunakan untuk mengetahui sejauhmana kemampuan aktiva yang dimiliki perusahaan bisa menghasilkan laba (Tandelilin,2001). ROA merupakan rasio antara laba bersih terhadap total aktiva. Semakin besar ROA menunjukkan kinerja perusahaan semakin baik. Investor percaya bahwa manajemen perusahaan telah menggunakan aktiva perusahaan secara efektif untuk menghasilkan laba bagi para pemiliknya.

Current ratio (CR) didapatkan dengan membandingkan nilai aset lancar dengan liabilitas lancar perusahaan. (Hendra Wicaksono, 2013 dalam Basalama, Murni, dan Sumarauw, 2017) $\mathrm{CR}$ yang terlalu tinggi menunjukan adanya kelebihan uang kas atau aktiva lancar lainnya dibandingkan dengan yang dibutuhkan sekarang. Apabila rasio lancar (CR) rendah, dapat dikatakan bahwa perusahaan kurang modal untuk membayar utang. Namun, apabila hasil pengukuran rasio tinggi, belum tentu kondisi perusahaan sedang baik. Hal ini dapat saja terjadi karena aktiva tidak digunakan sebaik mungkin. Jadi, Current Ratio dapat menunjukan sejauh mana aktiva lancar menjamin pembayaran dari kewajiban lancarnya (Kasmir, 2015:135 dalam Basalama, Murni, dan Sumarauw, 2017).

Kerangka pemikiran yang digunakan dalam penelitian ini adalah:

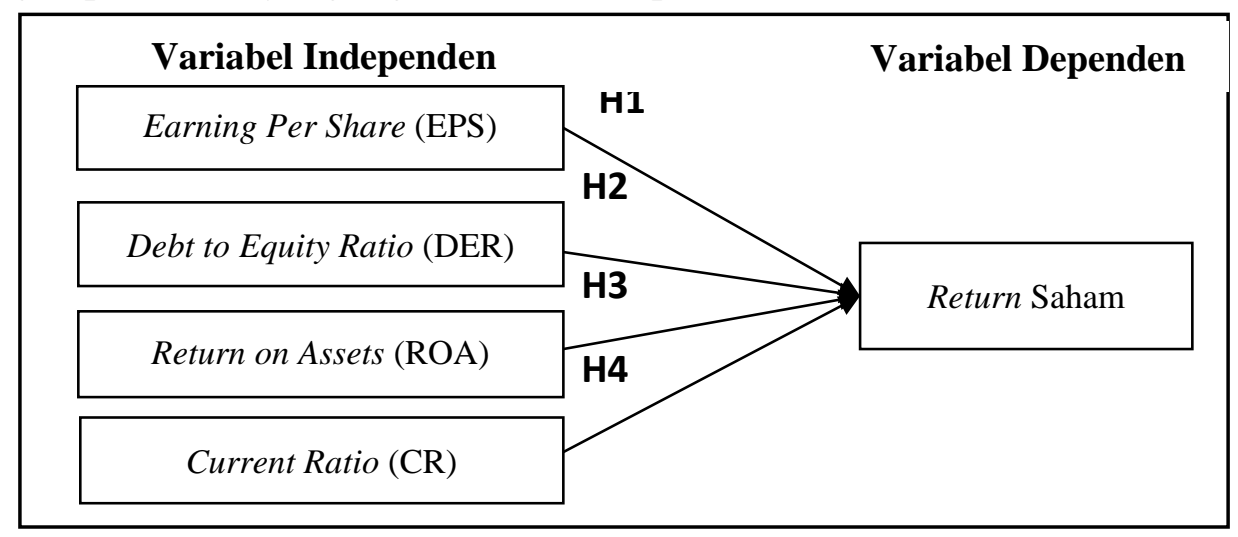

Hipotesis yang digunakan dalam penelitian ini adalah sebagai berikut:

H1: Earning Per Share berpengaruh positif signifikan terhadap Return Saham

H2: Debt to Equity Ratio berpengaruh negatif signifikan terhadap Return Saham

H3: Return On Assets berpengaruh positif signifikan terhadap Return Saham

H4: Current Ratio berpengaruh positif signifikan terhadap Return Saham

\section{METODOLOGI PENELITIAN}

Variabel independen pada penelitian ini adalah Earning Per Share (EPS) (X1), Debt to Equity Ratio (DER) (X2), Return On Assets (ROA) (X3), dan Current Ratio (CR) (X4). Sementara Return Saham merupakan variabel dependen. Data pada penelitian ini menggunakan data sekunder perusahaan manufaktur yang terdaftar pada BEI yang didapatkan dari situs resmi $w w w . i d x . c o . i d$ selama tiga periode yaitu 2015-2017.

Metode yang digunakan dalam pemilihan sampel dalam penelitian ini menggunakan metode purposive sampling atau metode tidak acak. Kriteria-kriteria pemilihan sampel yang digunakan dalam penelitian ini adalah: (a) Perusahaan manufaktur yang sudah terdaftar di Bursa Efek Indonesia (BEI) pada tahun 2015-2017, (b) Laporan keuangan perusahaan 
manufaktur yang berakhir pada tanggal 31 Desember dan sudah dipublikasikan, (c) Perusahaan manufaktur yang memiliki Earning Per Share (EPS) positif selama 2015-2017, dan (d) Perusahaan manufaktur yang menerbitkan laporan keuangan dalam mata uang Rupiah pada tahun 2015-2017.

Return saham merupakan hasil yang diperoleh dari investasi dengan cara menghitung selisih harga saham periode berjalan dengan periode sebelumnya dengan mengabaikan dividen. Return saham dihitung dengan rumus : (Ross et al, 2003)

Dimana :

$$
R i=\frac{(P t-[P t-1])}{P t-1}
$$

Ri $\quad=$ Return Saham

$\mathrm{Pt} \quad=$ Harga Saham periode $\mathrm{t}$

Pt-1 = Harga Saham periode t-1

Earning Per Share (EPS) menurut Fakhrudin dan Hardianto (2001) sebagaimana dikutip dari Arista (2012), dapat diketahui dengan rumus sebagai berikut:

$$
\text { Earning Per Share }(E P S)=\frac{\text { Earning after tax }}{\text { Jumlah saham yang beredar }}
$$

Debt to Equity Ratio (DER) dapat diketahui dengan rumus sebagai berikut (Brealey, 2001 dalam Michell Suharli 2005) :

$$
\text { Debt to Equity Ratio }(D E R)=\frac{\text { Total Debt }}{\text { Total Equity }}
$$

Return on Assets (ROA) menurut Syamsuddin (2007) sebagaimana dikutip dari Khoir, et al (2013) dapat diketahui dengan rumus sebagai berikut:

$$
\text { Return on Assets }(R O A)=\frac{\text { Laba Setelah Pajak }}{\text { Total Aktiva }}
$$

Current Ratio (CR) dapat diketahui dengan rumus sebagai berikut: (Sugiarti, et al, 2015)

$$
\text { Current Ratio }(C R)=\frac{\text { Aktiva Lancar }}{\text { Kewajiban Lancar }} \times 100 \%
$$

\section{HASIL DAN PEMBAHASAN}

Hasil uji statistik deskriptif pada perusahaan manufaktur periode 2015-2017 menunjukan bahwa nilai minimum pada Return Saham sebesar -52,75000, nilai maksimum sebesar 48,40764, mean 2,4449268, dan standar deviasi sebesar 19,89516094. Hasil statistik deskriptif EPS memiliki nilai minimum 0,06393, nilai maksimum 37424,24194, mean 780,5584715, dan standar deviasi 4099,27650310. Hasil statistik deskriptif berikutnya menunjukan DER memiliki nilai minimum 0,07613, nilai maksimum 4,94652, mean 0,8542118 , dan standar deviasi 0,77784019. Hasil statistik deskriptif ROA memiliki nilai minimum 0.00042, nilai maksimum 0,68275, mean 0,0891861, dan standar deviasi 0,09749661. Hasil statistik deskriptif CR memiliki nilai minimum sebesar 0,24068, nilai maksimum 15,16460, mean 2,6053684, dan standar deviasi 2,05685136.

Uji Normalitas. Penelitian ini menggunakan uji normalitas dengan One-sample Kolmogorov-Smirnov. Dalam penelitian ini, menunjukkan nilai sig.(2-tailed) $>0.05$ berarti data terdistribusi normal dan memenuhi asumsi normalitas.

Uji Multikolonieritas digunakan untuk menguji ada tidaknya multikolonieritas dilihat dari nilai tolerance atau VIF. Dari hasil pengolahan data untuk tahun 2015-2017 menghasilkan nilai tolerance $>0.10$ dan nilai VIF $<10$ untuk semua variabel maka persamaan model regresi tidak mengandung masalah multikolonieritas. 
Uji Heterokedastisitas bertujuan untuk melihat ada tidaknya heterokedastisitas yang dilihat dari nilai signifikansinya. Penelitian ini menggunakan uji heteroskedastisitas dengan Uji Glejser. Hasil pengolahan data menunjukkan hasil nilai signifikansi > 0.05 untuk semua variabel maka persamaan model regresi tidak mengandung heterokedastisitas.

Uji Autokorelasi bertujuan untuk melihat ada tidaknya autokorelasi dalam penelitian ini menggunakan Uji Durbin-Watson. Dari hasil pengolahan data, didapat nilai sig. yang terletak diantara batas atas atau nilai dU dan nilai 4-dU sehingga dapat disimpulkan bahwa persamaan model regresi tidak terjadi masalah autokorelasi.

Tabel 1

Koefisien Regresi

Coefficients $^{\mathrm{a}}$

\begin{tabular}{|c|c|c|c|c|c|c|}
\hline \multirow{2}{*}{\multicolumn{2}{|c|}{ Model }} & \multicolumn{2}{|c|}{ Unstandardized Coefficients } & \multirow{2}{*}{$\begin{array}{c}\text { Standardized Coefficients } \\
\text { Beta } \\
\end{array}$} & \multirow[t]{2}{*}{$\mathrm{t}$} & \multirow[t]{2}{*}{ Sig. } \\
\hline & & $\mathrm{B}$ & Std. Error & & & \\
\hline \multirow{5}{*}{1} & (Constant) & $-10,700$ & 4,157 & & $-2,574$ & 011 \\
\hline & EPS & 3,208 &, 000 & ,007 & 071 & ,943 \\
\hline & DER &,- 097 & 2,651 &,- 004 &,- 037 & ,971 \\
\hline & ROA & 39,784 & 16,381 & ,195 & 2,429 & 016 \\
\hline & $\mathrm{CR}$ & 1,829 & ,896 & , 189 & 2,040 & 043 \\
\hline
\end{tabular}

a. Dependent Variable: RETURN

Sumber : Output SPSS versi 21

Hasil Analisis Regresi Berganda pada penelitian ini, dapat disimpulkan persamaan model regresi yaitu:

$$
Y=-10,700+3,208 E P S-0,097 D E R+39,784 R O A+1,829 C R+\varepsilon
$$

Dari persamaan diatas, nilai constant sebesar -10,700. Hal ini menyatakan bahwa bila variabel EPS, DER, ROA, dan CR sama dengan nol atau diabaikan, maka Return Saham akan bernilai -10,700. Nilai koefisien regresi EPS bernilai positif sebesar 3,208 artinya setiap peningkatan EPS sebesar 1 satuan akan menaikan Return Saham sebesar 3,208 dengan asumsi variabel DER, ROA, dan CR adalah konstan. Dan berdasarkan hasil pengujian statistik dengan uji t menunjukkan bahwa variabel EPS berpengaruh positif tidak signifikan terhadap return saham. Nilai koefisien regresi DER bernilai negatif sebesar -0,097 artinya setiap peningkatan DER sebesar 1 satuan akan menurunkan Return Saham sebesar -0,097 dengan asumsi variabel EPS, ROA, dan CR adalah konstan. Hasil pengujian statistik dengan uji t menunjukkan bahwa variabel DER berpengaruh negatif tidak signifikan terhadap return saham. Nilai koefisien regresi ROA bernilai positif sebesar 39,784 artinya setiap peningkatan ROA sebesar 1 satuan akan menaikan Return Saham sebesar 39,784 dengan asumsi variable EPS, DER, dan CR adalah konstan. Hasil pengujian statistik dengan uji t menunjukkan bahwa variabel ROA berpengaruh positif signifikan terhadap return saham. Nilai koefisien regresi CR bernilai positif sebesar 1,829 artinya setiap peningkatan CR sebesar 1 satuan akan menaikan Return Saham sebesar 1,829 dengan asumsi EPS, DER, dan ROA adalah konstan. Hasil pengujian statistik dengan uji t menunjukkan bahwa variabel CR berpengaruh positif signifikan terhadap return saham.

Uji t adalah uji yang digunakan untuk menguji keterkaitan secara individu antara variabel bebas dengan variabel terikat. Untuk menguji hipotesis nol ditolak atau diterima, titik tolaknya adalah bila nilai $p$-value $t$-test $<$ atau $>0,05$, artinya jika nilai signifikansi dari variabel independen di bawah 0,05 , maka $\mathrm{H}_{0}$ ditolak dan $\mathrm{H}_{\mathrm{a}}$ diterima dan sebaliknya.

Uji Koefisien Determinasi (Adj. R-Square) untuk mengetahui persentase sumbangan variabel bebas secara serentak terhadap variabel terikat. Adjusted R Square sebesar 0,060 (dalam bentuk persentase sebesar 6\%). Sehingga disimpulkan bahwa variabel return saham 
dapat dijelaskan oleh variabel independen, yaitu EPS, DER, ROA, dan CR sebesar 6\%, sedangkan $94 \%$ sisanya dijelaskan oleh variabel atau faktor lain yang tidak dimasukkan dalam penelitian ini.

\section{KESIMPULAN DAN SARAN}

Dalam penelitian ini beberapa variabel dalam menganalisis return saham antara lain EPS, DER, ROA, dan CR. Dari beberapa faktor tersebut terbukti secara empiris bahwa EPS dan DER tidak berpengaruh secara signifikan terhadap return saham yang akan diterima investor. Sementara ROA dan CR berpengaruh signifikan terhadap return saham yang akan diterima investor.

Keterbatasan : (1) Penelitian hanya terbatas pada tiga periode yaitu 2015-2017. (2) Faktor yang mempengaruhi keputusan investor dalam menganalisa rasio keuangan perusahaan hanya mencakup sebagian, sementara banyak faktor lain yang dapat menganalisis return saham. (3) Sampel perusahaan yang diteliti yang jumlahnya relatif sedikit, yaitu hanya sebanyak 66 perusahaan manufaktur.

Saran : (1) Menggunakan periode pengamatan lebih dari tiga tahun agar rentang penelitian menjadi lebih luas dan hasil penelitian lebih akurat. (2) Menambah variabel independen lainnya yang belum digunakan dalam penelitian ini dan diperkirakan akan mempengaruhi return saham, seperti net profit margin, total assets turnover, dan variabelvariabel lainnya. (3) Memperbanyak jumlah sampel dan periode yang digunakan dalam penelitian agar kesimpulan yang dihasilkan lebih mencerminkan keadaan yang sebenarnya.

\section{DAFTAR PUSTAKA}

Brigham, Eugene F dan Houston. (2006). Fundamental of Financial Management: DasarDasar Manajemen Keuangan. Edisi 10. Jakarta: Salemba Empat.

Darmadji, Tjiptono, dan Fakhruddin. (2012). Pasar Modal di Indonesia. Edisi Ketiga. Jakarta: Salemba Empat.

Hadi, Nor. (2013). Pasar Modal (Acuan Teoritis dan Praktis Investasi di Instrumen Keuangan Pasar Modal). Yogyakarta: Graha Ilmu.

Michell Suharli. (2005). Studi Empiris Terhadap Dua Faktor yang Mempengaruhi Return Saham Pada Industri Food \& Beverages di BEJ. JURNAL AKUNTANSI \& KEUANGAN. 7 (2). 99-116.

Ross, A Stephen. Westerfield, Randolph W. Jordan, Bradford D. (2003). Fundamentals of Corporate Finance. Sixth edition. New York: Mc Graw-Hill.

Samsul, Mohammad. (2006). Pasar Modal dan Manajemen Portofolio. Surabaya: Erlangga.

Sugiarti, Surachman, dan Siti Aisjah. (2015). Pengaruh Kinerja Keuangan Perusahaan terhadap Return Saham (Studi pada Perusahaan Manufaktur yang Terdaftar di Bursa Efek Indonesia). Jurnal Aplikasi Manajemen (JAM). 13 (2). 283-298.

Tandelilin, Eduardus. (2010). Portofolio dan Investasi:Teori dan Aplikasi. Edisi Pertama. Yogyakarta: Kanisius. 